Article

\title{
Prediction of Tensile Strength and Deformation of Diffusion Bonding Joint for Inconel 718 Using Deep Neural Network
}

\author{
Han Mei ${ }^{1,2}$, Lihui Lang ${ }^{2,3, *}$, Xiaoxing Li $^{3}$, Hasnain Ali Mirza ${ }^{3}$ and Xiaoguang Yang ${ }^{1,2}$ (D) \\ 1 School of Energy and Power Engineering, Beihang University, Beijing 100191, China; \\ mh7196@126.com (H.M.); yxg@buaa.edu.cn (X.Y.) \\ 2 Collaborative Innovation Center of Advanced Aero-Engine, Beijing 100191, China \\ 3 School of Mechanical Engineering and Automation, Beihang University, Beijing 100191, China; \\ li.xiaoxing@buaa.edu.cn (X.L.); hassnain@buaa.eud.cn (H.A.M.) \\ * Correspondence: langlhb425@163.com; Tel.: +86-010-823-16821
}

Received: 3 August 2020; Accepted: 14 September 2020; Published: 18 September 2020

\begin{abstract}
Due to the acceptable high-temperature deformation resistance of Inconel 718, its welding parameters such as bonding temperature and pressure are inevitably higher than those of general metals. As a result of the existing punitive processing environment, it is essential to control the deformation of parts while ensuring the bonding performance. In this research, diffusion bonding experiments based on the Taguchi method (TM) are conducted, and the uniaxial tensile strength and deformation ratio of the experimental joints are measured. According to experimental data, a deep neural network (DNN) was trained to characterize the nonlinear relationship between the diffusion bonding process parameters and the diffusion bonding strength and deformation ratio, where the overall correlation coefficient came out to be 0.99913 . The double-factors analysis of bonding temperature-bonding pressure based on the prediction results of the DNN shows that the temperature increment of the diffusion bonding of Inconel 718 significantly increases the deformation ratio of the diffusion bonding joints. Therefore, during the multi-objective optimization of the bonding performance and deformation of components, priority should be given to optimizing the bonding pressure and duration only.
\end{abstract}

Keywords: Inconel 718; diffusion bonding; deep neural network; lattice porous structure; performance forecast

\section{Introduction}

Inconel 718 is a precipitation hardening reinforced nickel-base alloy [1]. As a result of its good impact strength, fatigue strength, and fracture toughness under $650{ }^{\circ} \mathrm{C}$, it is often used to manufacture high-temperature large-scale components of aerospace engines and aerospace rocket engines, such as combustion chamber guide blades and turbine disks [2]. The utilization of Inconel 718, as the most widely used nickel-based alloy, is about $35 \%$ of the total amount of wrought superalloys [3]. In recent years, with the in-depth research on the material and the development of processing technology, Inconel 718 has also been used to manufacture lattice porous structures (LPSs) to meet the needs of lightweight components and parts, such as honeycomb panels, lattice truss structures, and corrugated plates [4].

Diffusion bonding is currently one of the most effective processing methods to weld superalloys. By applying pressure to the surface of the material to be bonded at high temperature, it undergoes small plastic rheology and close contact; then, it forms a metallurgical bond through atomic diffusion for a certain period of time [5]. The main process parameters affecting the performance of diffusion bonding 
include the bonding temperature, bonding pressure, and duration. Zhang et al. conducted diffusion bonding experiments of Inconel 718 in the range of $910-1000{ }^{\circ} \mathrm{C}$ and uniaxial tension experiments on welded joints [6]. The results show that the tensile strength and elongation of the welded joint increase with the increase of bonding temperature before it reaches the dynamic recrystallization temperature of the base metal, while it does not increase significantly after the bonding pressure and duration reach the rated value. Li et al. [7] increased the diffusion bonding temperature (1050-1100 $\left.{ }^{\circ} \mathrm{C}\right)$ to shorten the bonding duration. It is observed that when the experimental parameters are adjusted too high, the flow stress decreases, which results in a significant increase of the deformation ratio. It can be seen that the deformation resistance of Inconel 718 at high temperature forces the diffusion process to be carried out in a high-temperature and high-pressure environment. However, if the creep degree of the material is intensified at high temperature, the parts will deform to a large degree.

In the manufacturing process of LPS, more than 5\% deformation [7] may cause serious damage to its internal structure. Some researchers have realized transient liquid phase (TLP) bonding by adding a nickel-based foil interlayer between welding materials. This method can reduce the bonding temperature and bonding pressure of diffusion bonding under the condition of ensuring the strength, and it can also relieve the deformation degree of the parts [2-4,8,9]. However, the enhanced fluidity of the intermediate layer material in liquid phase will also block and destroy the microchannel inside the porous lattice structure during TLP bonding. Through the multi-objective optimization of the performance and deformation degree of the diffusion bonding process, several sets of parameters that meet the strength requirements and do not cause an excessive distortion of parts can be found. These parameters are called Pareto solutions in multi-objective optimization problems [10-12]. Obviously, in order to realize the multi-objective optimization of the diffusion bonding process, it is necessary to establish a fast response model between the bonding parameters (bonding temperature, bonding pressure, duration) and diffusion bonding performance and deformation ratio.

The complex nonlinear relationship between the bonding parameters and bonding performance is difficult to characterize by the traditional linear regression method. Neural network is a nonlinear statistical data modeling tool for solving nonlinear stochastic problems. The ability to accurately characterize the complex constraint relationship between input and output give it an obvious advantage in characterizing nonlinear relations [13,14]. The trained neural network model can also be used to accurately predict the response of bonding strength (output) to the setting (input) of process parameters [15-17]. On the basic of a series of experiments of AA5083 and AA7075 aluminum alloy and training neural network, Sagai et al. predicted the tensile strength and shear strength of joints under different bonding parameters [18]. Lin et al. conducted research on the optimization of weld geometry of Inconel 718 GTA. The Taguchi method (TM) was used to obtain the optimal solution within the specified control factor level and determine the magnitude of neural network input. The results show that the design of neural network training samples in the feasible solution region constrained by the Taguchi method (TM) can greatly improve the learning efficiency and accuracy of neural network [19].

In this research, based on the optimal welding parameters obtained by TM orthogonal experiments, several groups of Inconel 718 diffusion bonding experiments were carried out by changing the bonding temperature, pressure, and duration. The tensile strength of diffusion bonding samples was obtained by the uniaxial tensile test. The neural network was trained by a back-propagation algorithm, and the trained neural network can quickly predict the bonding strength and deformation based on the input process parameters. The quick response model between process parameters and welding strength is established by a trained neural network; then, the double-factors analysis of three bonding parameters is conducted.

\section{Experiments}

This investigation uses a wrought Inconel 718 alloy subjected to solution treatment (holding at $1020^{\circ} \mathrm{C}$ for $2 \mathrm{~h}$ ) and aging treatment (holding at $720^{\circ} \mathrm{C}$ for $8 \mathrm{~h}$, cooling to $620^{\circ} \mathrm{C}$, and then holding for $18 \mathrm{~h}$, air cooling). The composition and proportion of material elements are shown in Table 1. 
The specimens to be bonded are machined into two $\Phi 30 \mathrm{~mm} \times 40 \mathrm{~mm}$ cylinders by Electrical discharge machining. To facilitate the measurement of tensile strength, the cylinder specimens are bonded in the butt joint form, as shown in Figure 1. The experiments were carried out on vacuum diffusion bonding equipment with a maximum working temperature of $1400{ }^{\circ} \mathrm{C}$, as shown in Figure 2 . The temperature is controlled by a proportion integration differentiation (PID) controller, and the control precision is $\pm 1{ }^{\circ} \mathrm{C}$. The highest vacuum degree is $1.2 \times 10^{-3} \mathrm{~Pa}$. After polished by 500\# to 2000\# sandpaper, the bonding faces of specimens will be chemical pickled by a mixed solution of hydrochloric acid and nitric acid to remove surface oxide layers. Finally, the parts were cleaned with acetone [7].

Table 1. Chemical composition (wt \%) of Inconel 718.

\begin{tabular}{cccccccccccc}
\hline $\mathbf{C}$ & $\mathbf{S i}$ & $\mathbf{C r}$ & $\mathbf{N i}$ & $\mathbf{M o}$ & $\mathbf{N b}$ & $\mathbf{T i}$ & $\mathbf{A l}$ & $\mathbf{F e}$ & $\mathbf{B}$ & $\mathrm{Zr}$ & $\mathbf{N}$ \\
\hline 0.002 & 0.31 & 18.25 & 53.6 & 3.1 & 4.12 & 0.96 & 0.6 & 18.34 & 0 & 0 & 0.718 \\
\hline
\end{tabular}

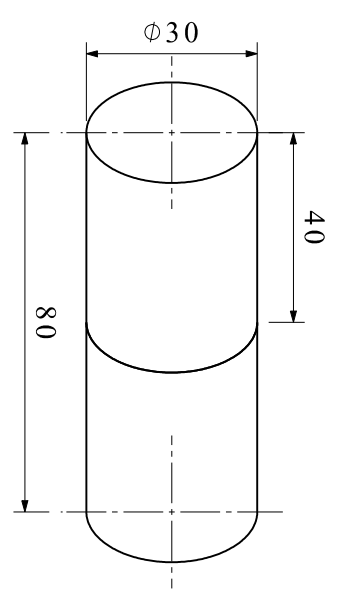

Figure 1. Schematic diagram of bonding structure (unit: $\mathrm{mm}$ ).

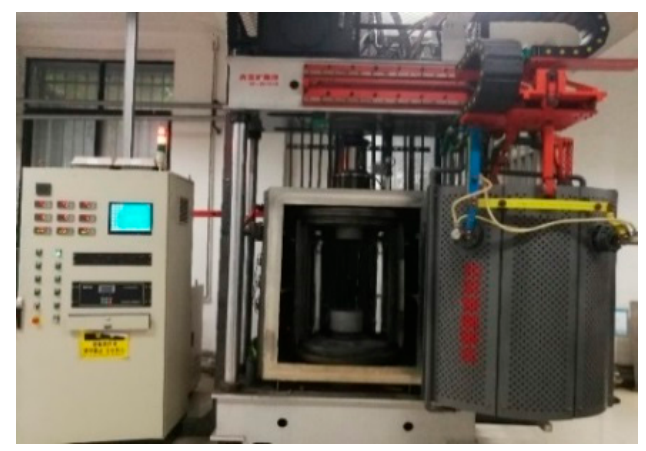

Figure 2. Vacuum diffusion bonding equipment.

The main purpose of the diffusion bonding experiment is to provide samples for training the neural network, which should be able to accurately characterize the relationship between the response and input variables in the appropriate range of process parameters. The number of experiments can be effectively reduced by selecting samples in the range of the feasible welding parameters centered on the optimal welding parameters. The Taguchi method (TM) is a multi-factor experimental design method proposed by famous Japanese statistician Taguchi Genichi [20]. This method can analyze the influence of a single factor and its horizontal component on the experimental results with very few experiments; then, a set of optimal parameters is estimated. There were two periods in this experiment. In the first period, orthogonal experiments were designed according to TM, and three levels were selected for each of the three parameters for diffusion bonding experiments, as shown in Table 2. In the second period, centering on optical welding process parameters that were determined by TM orthogonal analysis, 
the welding experiments were expended from nine groups to 32 groups, and the ratio of the training set/verification set/test set of the neural network was 70:15:15\%.

Table 2. Tensile strength and deformation ratio.

\begin{tabular}{|c|c|c|c|c|c|c|c|c|}
\hline \multicolumn{3}{|c|}{ Parameter } & \multicolumn{4}{|c|}{ Tensile Strength (MPa) } & \multirow[b]{2}{*}{$\begin{array}{c}\text { Deformation } \\
\text { Ratio (\%) }\end{array}$} & \multirow{2}{*}{$\begin{array}{c}\text { Taguchi } \\
\text { Experiment } \\
(\mathrm{Y} / \mathrm{N})\end{array}$} \\
\hline $\begin{array}{c}\text { Bonding } \\
\text { Temperature } \\
\left({ }^{\circ} \mathrm{C}\right)\end{array}$ & $\begin{array}{l}\text { Bonding } \\
\text { Pressure } \\
\text { (MPa) }\end{array}$ & $\begin{array}{l}\text { Duration } \\
\text { (min) }\end{array}$ & $\begin{array}{c}\text { Sample } \\
1\end{array}$ & $\begin{array}{c}\text { Sample } \\
2\end{array}$ & $\underset{3}{\text { Sample }}$ & $\begin{array}{l}\text { Average } \\
\text { Value }\end{array}$ & & \\
\hline 1000 & 20 & 30 & 195.26 & 195.14 & 195.21 & 195.20 & 98.628 & $\mathrm{Y}$ \\
\hline 1000 & 30 & 60 & 325.55 & 326.79 & 327.00 & 326.45 & 97.570 & $\mathrm{Y}$ \\
\hline 1000 & 40 & 90 & 414.37 & 413.61 & 413.49 & 413.82 & 95.525 & $\mathrm{Y}$ \\
\hline 1050 & 20 & 60 & 326.69 & 325.73 & 325.66 & 326.03 & 97.885 & $\mathrm{Y}$ \\
\hline 1050 & 30 & 90 & 488.73 & 485.34 & 478.10 & 484.06 & 96.178 & $\mathrm{Y}$ \\
\hline 1050 & 40 & 30 & 519.33 & 520.07 & 519.99 & 519.80 & 96.432 & $\mathrm{Y}$ \\
\hline 1070 & 25 & 105 & 481.65 & 491.47 & 502.26 & 491.79 & 97.032 & $\mathrm{~N}$ \\
\hline 1070 & 40 & 30 & 587.99 & 584.61 & 583.12 & 585.24 & 96.332 & $\mathrm{~N}$ \\
\hline 1070 & 40 & 90 & 596.86 & 605.91 & 612.76 & 605.18 & 96.117 & $\mathrm{~N}$ \\
\hline 1090 & 25 & 25 & 441.52 & 438.56 & 438.25 & 439.44 & 98.053 & $\mathrm{~N}$ \\
\hline 1090 & 35 & 90 & 651.10 & 657.93 & 652.75 & 653.93 & 94.490 & $\mathrm{~N}$ \\
\hline 1090 & 40 & 75 & 681.07 & 682.23 & 672.18 & 678.49 & 93.850 & $\mathrm{~N}$ \\
\hline 1100 & 20 & 45 & 399.54 & 399.15 & 395.86 & 398.18 & 97.316 & $\mathrm{~N}$ \\
\hline 1100 & 20 & 90 & 442.50 & 442.91 & 443.29 & 442.90 & 95.502 & $\mathrm{Y}$ \\
\hline 1100 & 30 & 30 & 535.02 & 536.53 & 535.06 & 535.54 & 96.970 & $Y$ \\
\hline 1100 & 30 & 60 & 591.14 & 588.75 & 591.46 & 590.45 & 95.040 & $\mathrm{~N}$ \\
\hline 1100 & 30 & 105 & 637.10 & 637.81 & 637.58 & 637.50 & 92.673 & $\mathrm{~N}$ \\
\hline 1100 & 30 & 120 & 650.90 & 651.68 & 651.49 & 651.36 & 92.322 & $\mathrm{~N}$ \\
\hline 1100 & 35 & 90 & 679.22 & 680.18 & 679.63 & 679.68 & 91.679 & $\mathrm{~N}$ \\
\hline 1100 & 40 & 45 & 660.22 & 662.73 & 660.26 & 661.07 & 93.157 & $\mathrm{~N}$ \\
\hline 1100 & 40 & 60 & 679.05 & 679.49 & 678.58 & 679.04 & 91.923 & $\mathrm{Y}$ \\
\hline 1100 & 40 & 75 & 696.12 & 696.84 & 695.40 & 696.12 & 91.148 & $\mathrm{~N}$ \\
\hline 1100 & 40 & 90 & 708.03 & 709.13 & 710.67 & 709.28 & 90.961 & $\mathrm{~N}$ \\
\hline 1100 & 50 & 30 & 676.21 & 670.52 & 662.86 & 669.86 & 91.269 & $\mathrm{~N}$ \\
\hline 1100 & 50 & 90 & 712.88 & 712.31 & 712.89 & 712.69 & 90.260 & $\mathrm{~N}$ \\
\hline 1110 & 20 & 45 & 429.99 & 427.77 & 408.20 & 421.99 & 96.061 & $\mathrm{~N}$ \\
\hline 1110 & 40 & 60 & 699.05 & 694.95 & 688.21 & 694.07 & 88.532 & $\mathrm{~N}$ \\
\hline 1110 & 40 & 90 & 736.87 & 730.49 & 737.26 & 734.87 & 86.705 & $\mathrm{~N}$ \\
\hline 1130 & 25 & 75 & 573.94 & 572.28 & 522.15 & 556.12 & 84.391 & $\mathrm{~N}$ \\
\hline 1130 & 40 & 45 & 681.98 & 684.19 & 679.09 & 681.75 & 82.544 & $\mathrm{~N}$ \\
\hline 1130 & 40 & 90 & 773.10 & 757.64 & 775.32 & 768.69 & 78.412 & $\mathrm{~N}$ \\
\hline 1150 & 35 & 90 & 730.63 & 716.19 & 732.23 & 726.35 & 74.762 & $\mathrm{~N}$ \\
\hline
\end{tabular}

Three tensile specimens were taken from each welded specimen near the center by the EDM equipment. Uniaxial tensile tests were conducted on a ZWICK universal tensile testing machine (the maximum load capacity is $20 \mathrm{kN}$ ). The test was carried out at room temperature, and the loading speed was $3 \mathrm{~mm} / \mathrm{s}$. In order to ensure the uniformity of the bonding strength, the average value of the tensile strength of the three tensile samples is taken as the output value of the sample. Figure 3 shows part of the specimens after the tensile test. The formability degree of welding can be determined by measuring the height before and after diffusion bonding, namely height after welding/height before welding.

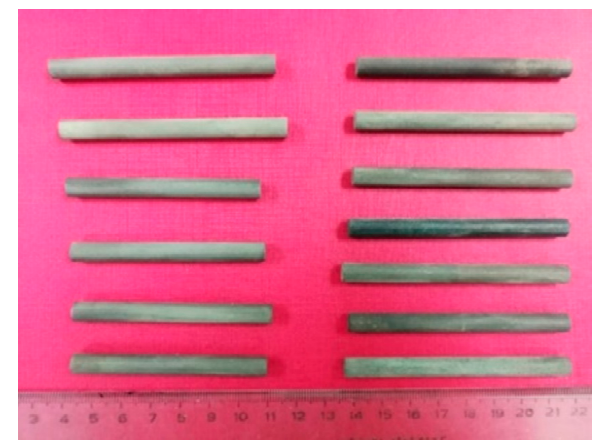

Figure 3. Part of specimens after the uniaxial tensile experiment. 


\section{Result and Discussion}

\subsection{Experiment Results}

The 32 groups of experimental data of tensile strength and deformation ratio are shown in Table 2, among which the nine groups of data signed $Y$ are Taguchi orthogonal test data.

Table 3 shows the results taken from orthogonal analysis of the nine groups of experiment data. This orthogonal analysis contains bonding temperature, bonding pressure, and duration, each of which contains three horizontal components. $K_{i}$ is the sum of experiment results of parameters from each parameter level $(I=1,2,3)$. Then, the horizontal component average value of every parameter is:

$$
k_{i}=K_{i} / 3 .
$$

Table 3. Result of Taguchi method (TM) orthogonal analysis.

\begin{tabular}{cccc}
\hline No. & Temperature $\left({ }^{\circ} \mathbf{C}\right)$ & Pressure (MPa) & Time (Min) \\
\hline K1 & 935.47 & 964.13 & 1250.54 \\
K2 & 1329.89 & 1346.04 & 1331.51 \\
K3 & 1657.47 & 1612.66 & 1340.78 \\
k1 & 311.82 & 321.38 & 416.85 \\
k2 & 443.30 & 448.68 & 443.84 \\
k3 & 552.49 & 537.55 & 446.93 \\
R & 722.00 & 648.53 & 90.24 \\
\hline
\end{tabular}

The range $(R)$ is the difference between the maximum and minimum horizontal components of the same element.

$$
R=\max \left\{K_{i}\right\}-\min \left\{K_{i}\right\}(i=1,2,3)
$$

The range $(R)$ is used to characterize the influence of the element on the experimental results. In this experiment, the range $(R)$ of the bonding temperature is slightly bigger than the bonding pressure and significantly bigger than the duration. It can be seen that the bonding temperature is the most important factor affecting the diffusion bonding strength of Inconel 718, and the effect of the diffusion bonding pressure is second only to that of the bonding temperature. According to the comparison of the average values of horizontal components, it can be seen that the tensile strength of bonding joints increases obviously with the increase of bonding temperature and bonding pressure. The tensile strength has a weak response to the duration, but it also increases slowly with the extension of the duration. In addition, the analysis of the deformation ratio of the joints shows that when the bonding temperature reaches $1100^{\circ} \mathrm{C}$ or the bonding pressure reaches $40 \mathrm{MPa}$, the deformation ratio of the parts is close to $90 \%$ and reaches the acceptance limit [7]. Therefore, taking $1100{ }^{\circ} \mathrm{C} / 40 \mathrm{MPa} / 90 \mathrm{~min}$ as the center, 23 groups of supplementary experiments were designed again to expand the experimental data samples. The parameters and experimental results are shown in Table 2. It can be seen from the experiment results that there is a complex nonlinear relationship between the tensile strength and deformation of diffusion bonding joints and three process parameters, which make it unable to accurately predict the change of tensile strength and deformation value from the change of one parameter.

Therefore, it is necessary to establish a neural network system with bonding temperature, bonding pressure, and duration as input and tensile strength and deformation as output.

\subsection{Establishment of Neural Network}

Due to the large difference of magnitude between the three groups of input parameters and the two groups of output parameters in this experiment, it is necessary to normalize the data before training to prevent the gradient explosion and gradient disappearance. In this experiment, the five 
groups of data were normalized in between 0 and 1 . The normalized data were used to train a deep neural network (DNN) based on a back-propagation algorithm. The three nodes in the input layer were the bonding temperature, pressure, and the duration, and the two nodes in the output layer were the bonding strength and deformation. By adjusting the number of hidden layers, the number of neurons in the hidden layers, and the transfer function of the neural network, several model construction schemes were obtained. The final model was determined by weighing the prediction accuracy and training efficiency under different schemes. The Levenberg-Marquardt (L-M) method was used in training the neural network. The characteristic of quick convergence while taking up lots of memory makes this method pretty suitable for training a small sample set.

Finally, the structure of the trained deep neural network model was 3-5-2-2 (a hidden layer with seven neurons, a hidden layer with two neurons), as shown in Figure 4. The 'tansig' was used as the transfer function in two hidden layers, and the 'purelin' was used in the output layer.

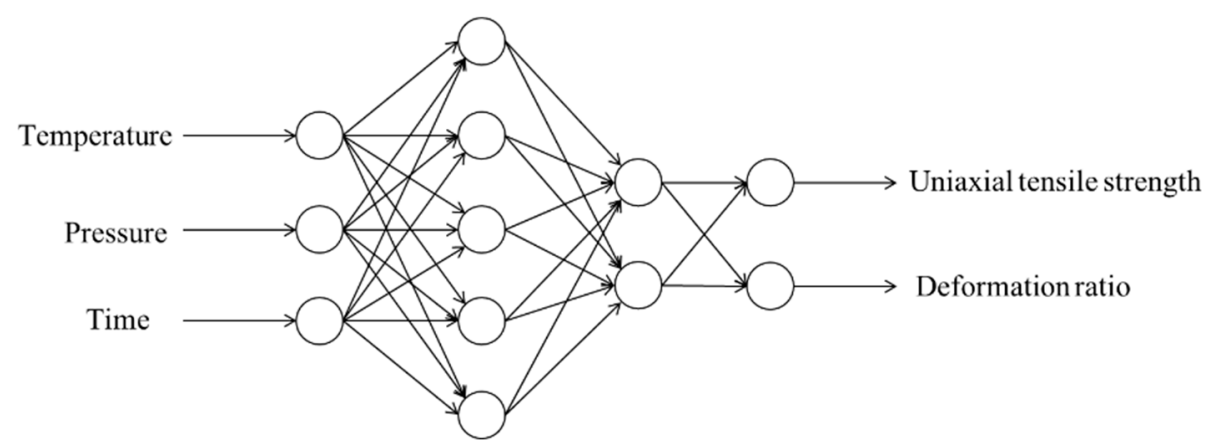

Figure 4. 3-5-2-2 structure of the deep neural network model.

Based on the early stop technology, the DNN model is terminated at 180 iterations, while the performance of the verification set did not degrade for 50 consecutive times. The best verification set performance was obtained at the 130th iteration, and the mean squared error (MSE) was $1.35 \times 10^{-4}$. The convergence process of the performance of the training set and verification set with iteration is shown in Figure 5. The regression performance analysis of the neural network training set, verification set, and test set in Figure 6 shows that the DNN model can accurately predict the diffusion bonding strength and joint deformation value, and the overall correlation coefficient is 0.99913 . Furthermore, the correlation coefficient of the test set is 0.98515 , which shows that the DNN model has excellent generalization ability.

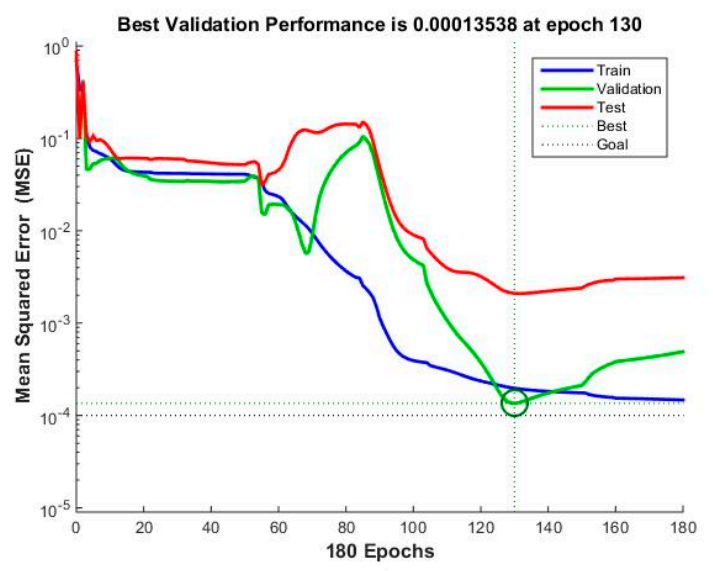

Figure 5. The convergence curve of mean squared error (MSE) with iteration during training the deep neural network (DNN) model. 

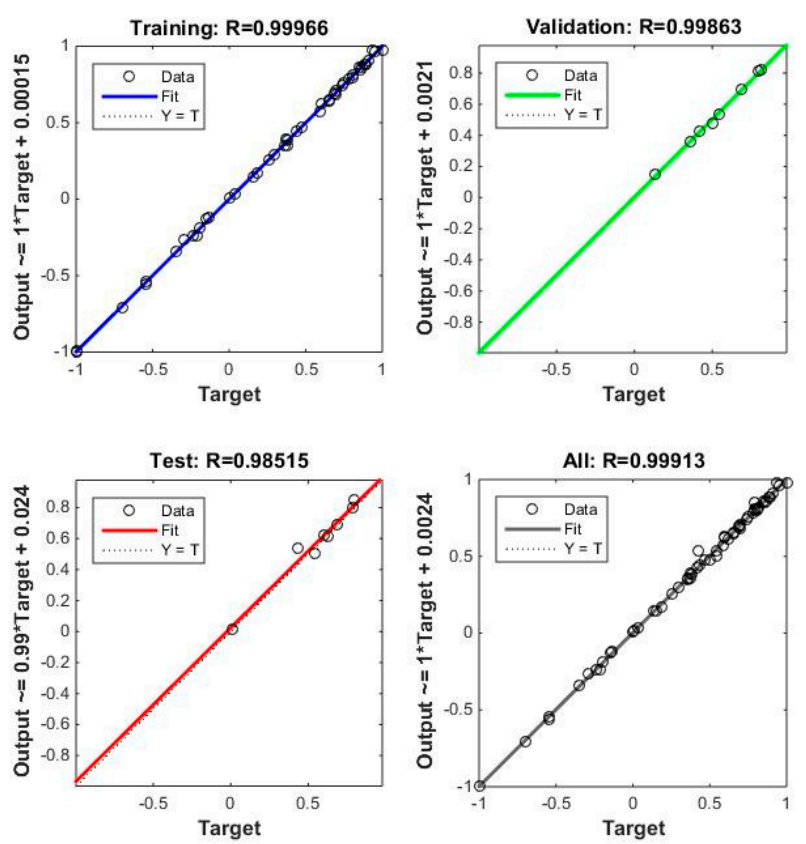

Figure 6. The regression performance analysis of the DNN model.

\subsection{Double-Factors Analysis Based on Prediction Data of DNN Model}

From orthogonal analysis, it can be seen that the influence weight of the bonding temperature and bonding pressure is close. Obviously, the bonding temperature and bonding pressure have a coupling effect on the bonding performance and deformation, which makes it difficult to judge their influence by single-factor analysis. Meanwhile, the influence weight of duration is significantly lower than that of the bonding temperature and bonding pressure. Additionally, the duration are often set with the heat treatment cycle of base metal to ensure its welded strength [2]. Therefore, duration was taken as a constant in this study, and the double-factors influence of temperature and pressure on welding performance was given priority.

The trained DNN model can predict the tensile strength and deformation ratio of bonding joints in the temperature range of $1050-1150{ }^{\circ} \mathrm{C}$ and the pressure range of $20-50 \mathrm{MPa}$. The input matrix was composed by uniformly selecting temperature values and pressure values within this range, and the duration was constant for 30,60, and $90 \mathrm{~min}$. Three sets of input matrices were fed into the DNN model, and the prediction results were plotted as a contour map, as shown in Figures 7 and 8.

It can be seen from the analysis of the double-factors contour map of the tensile strength of diffusion bonding joints in Figure 7 that there is a bonding failure region (BFR) of the Inconel 718 diffusion bonding process where the bonding temperature is lower than $1060{ }^{\circ} \mathrm{C}$ or the bonding pressure is lower than $25 \mathrm{MPa}$. In the BFR, the tensile strength of joints is not ideal. The generation of BFR is related to the temperature and pressure dependence of the diffusion mechanism. On one hand, the atoms do not have enough thermal activation energy because of the low temperature at the contact surface, which leads to an insufficient diffusion of elements at the interface and makes it difficult to form stable metallurgical bonding. While, on the other hand, the lower initial pressure makes the rough surface synapses fail to yield completely in the contact process, and many large continuous holes are formed at the interface. Some holes cannot be completely eliminated in the diffusion bonding process when the initial size of these holes is larger than a certain limit value, which reduces the bonding strength. Therefore, as long as either of the two factors (temperature and pressure) is in the BFR, it is difficult to significantly improve the performance of diffusion bonding by increasing either factor. By comparing Figure $7 \mathrm{a}$ with Figure $7 \mathrm{c}$, it can be seen that the increase of duration can reduce the pressure boundary of the BFR, but the effect is not significant. 


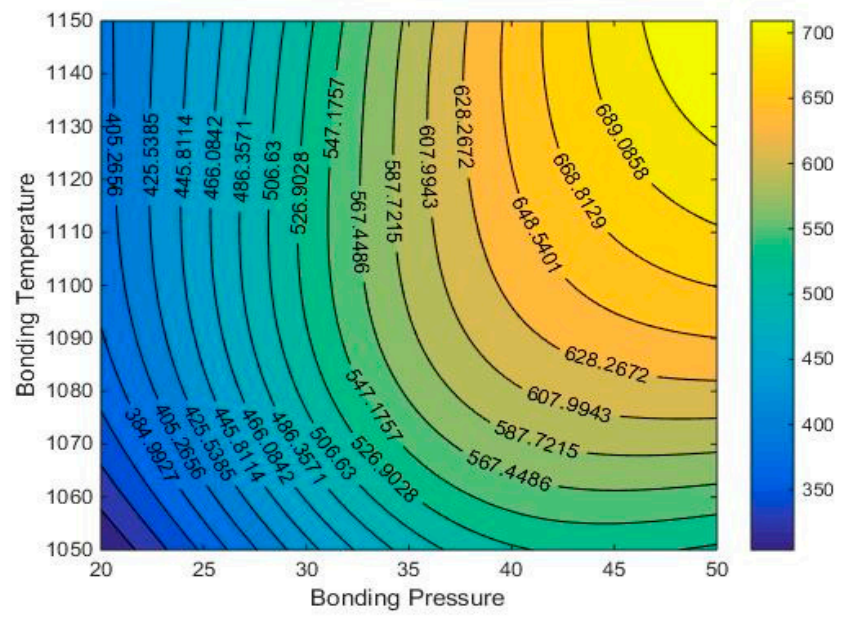

(a)

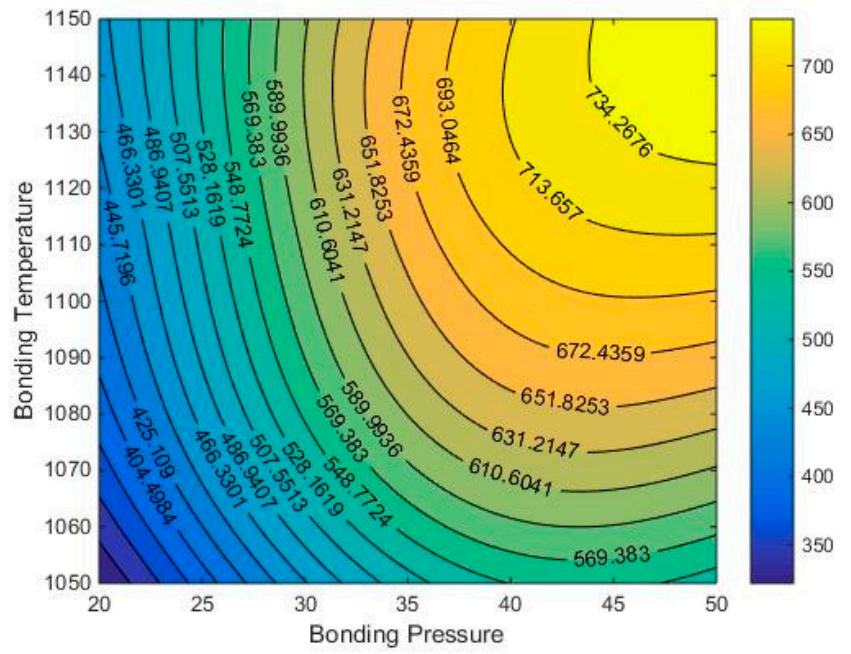

(b)

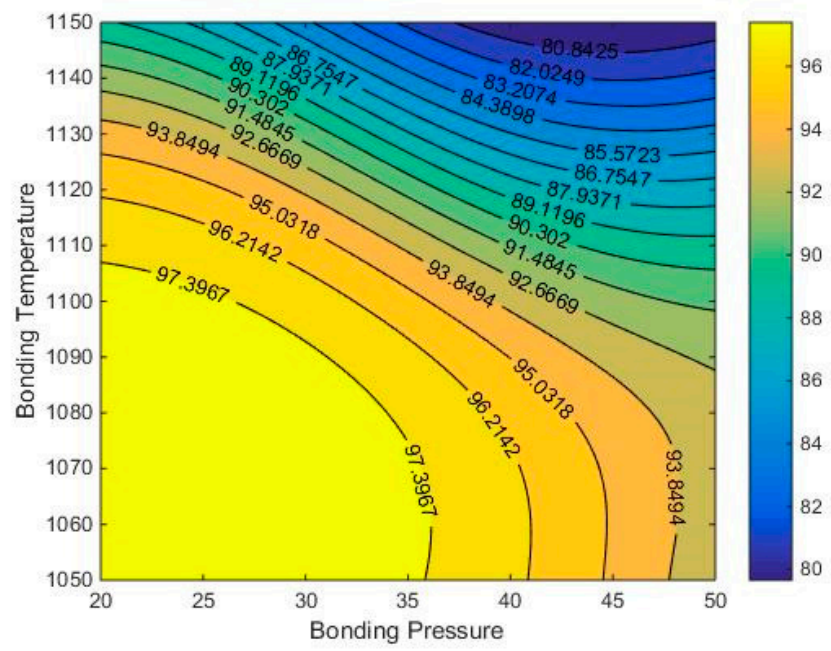

(c)

Figure 7. The double-factors contour map of tensile strength: $(\mathbf{a}) \mathrm{t}=30 \mathrm{~min} ;(\mathbf{b}) \mathrm{t}=60 \mathrm{~min} ;(\mathbf{c}) \mathrm{t}=90 \mathrm{~min}$. 


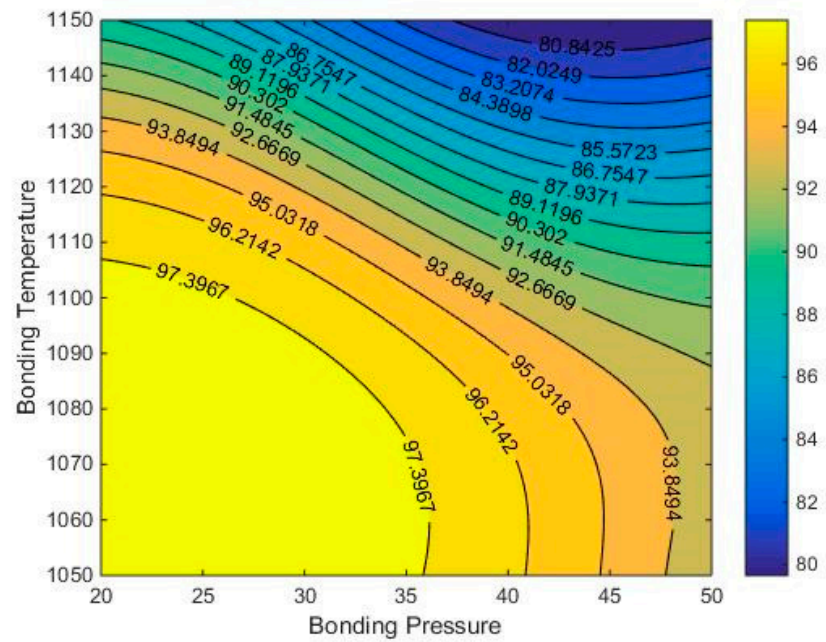

(a)

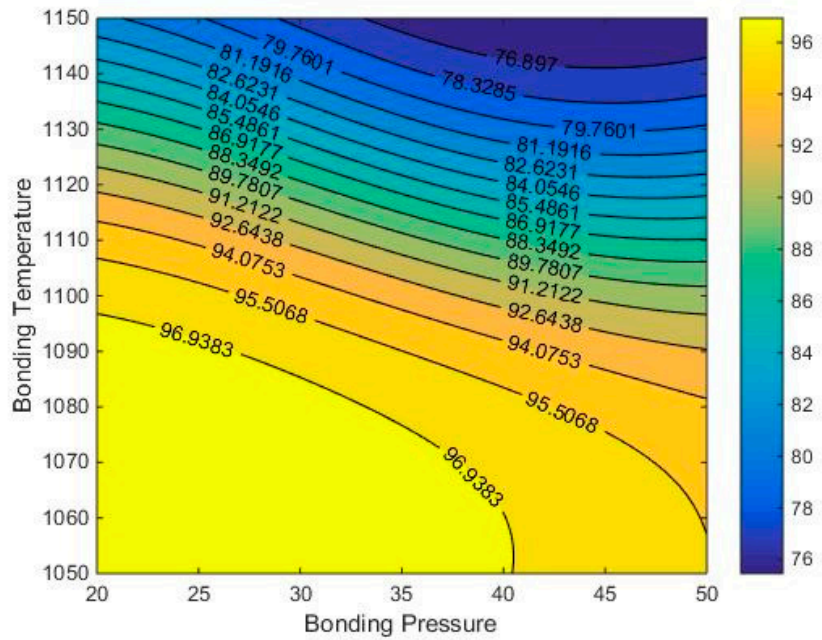

(b)

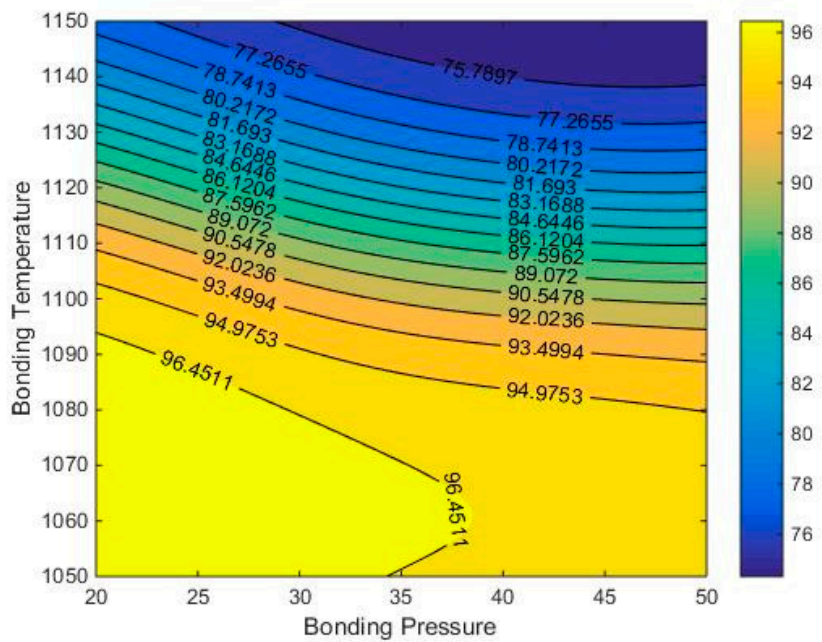

(c)

Figure 8. The double-factors contour map of deformation ratio: (a) $t=30 \mathrm{~min}$; (b) $t=60 \mathrm{~min}$; (c) $\mathrm{t}=90 \mathrm{~min}$. 
When the input parameters of diffusion bonding are not in the BFR, the tensile strength of the diffusion bonding joints can be significantly improved with the increase of temperature or pressure level. The holes at the interface will close rapidly and disappear with the effect of creep as the temperature increases. With the disappearance of the pinning effect because of the holes, grain boundary migration occurs at the interface, and the original bonding interface disappears [17]. The effect of pressure on the bonding performance is different from that of temperature. The increase of pressure greatly reduces the size of the initial holes and accelerates the closure of the holes by affecting the creep rate of the material. It can be seen form Figure 7a that with the continuous increase of temperature and pressure, the tensile strength of the joint continues to approach its maximum value. However, the effect of increasing the pressure and temperature is not unlimited. It can be seen from Figure $7 \mathrm{~b}, \mathrm{c}$ that the diffusion bonding strength begins to decline when the temperature and pressure levels exceed $1130{ }^{\circ} \mathrm{C}$ and $45 \mathrm{MPa}$, respectively. Firstly, the continuous increase of temperature leads to a serious growth of grain, which eventually results in the decline of the overall properties of Inconel 718. Meanwhile, the diffusion process is also interfered by the plastic deformation caused by high pressure. In addition, it can be seen from Figure $7 \mathrm{c}$ that the optimal parameter point of the diffusion bonding strength shifts to the lower right corner of the contour map compared with Figure $7 \mathrm{a}$, indicating that the increase of duration can effectively reduce the temperature and pressure levels needed for optimal connection strength.

In order to suppress joint deformation, the temperature also cannot be raised indefinitely. It can be seen from Figure 8 that the compression deformation of the bonding joints is affected by the coupling of bonding temperature and pressure, and the deformation ratio is small (maintained at about $96 \%$ ) in the range of bonding temperature below $1100^{\circ} \mathrm{C}$. When the bonding temperature is higher than $1100{ }^{\circ} \mathrm{C}$, it plays a decisive role in the change of the deformation ratio. The deformation ratio increases sharply with the increasing bonding temperature. This is because the softening rate induced by dynamic recovery (DRV) is significantly enhanced in a high-temperature environment, counteracting the effect of work hardening. It also results in a decrease in its flow stress, which reduces the deformation resistance of the material. By comparing the contour maps in Figure 8, it can be observed that the deformation ratio increases with the increase of duration at all the same coordinate points. In addition, the low deformation ratio region in Figure $8 \mathrm{c}$ is significantly reduced compared to Figure 8a, but the span of the deformation ratio at the same temperature increment becomes larger. This shows that the increase in duration can not only aggravate the deformation of the bonding joints, but also further increase the weight of the influence of temperature, which is caused by the sensitivity of the high-temperature creep deformation behavior of the material to temperature and time increments. Although the deformation ratio is insensitive to bonding pressure changes at bonding temperatures above $1100{ }^{\circ} \mathrm{C}$, the increase in pressure will still cause a sharp increase in the deformation of the joints under a lower diffusion bonding temperature. Similarly, the increase in duration will exacerbate the influence.

In summary, when optimizing the performance of diffusion bonding, the two process parameters of the increasing bonding pressure and duration can be given priority. Although the increase of temperature can significantly improve the strength of the diffusion bonding, it can also cause serious joint deformation problems.

\section{Conclusions}

The following conclusions can be derived from this study:

(1) Through TM analysis of the diffusion bonding experiment results under different parameters, it is found that the influence weight on the bonding performance of the bonding temperature is slightly larger than that of the bonding pressure, while the influence weight of duration is very small.

(2) The 3-5-2-2 structure deep neural network model trained based on multiple sets of process test data can accurately characterize the nonlinear relationship between the bonding process parameters and bonding performance, and its overall correlation coefficient reaches 0.99913. It can be used to predict the tensile strength and deformation ratio of diffusion joints. 
(3) The prediction results of the DNN model were plotted as contour maps of the bonding temperature and bonding pressure, and the temperature-pressure double-factors analysis was performed. The analysis results show that the initial selection of the diffusion bonding process parameters should avoid the bonding failure region (BFR). The deformation ratio of the diffusion bonding joints is sensitive to the bonding temperature. In order to meet the needs of increasing the strength of the diffusion bonding, priority can be given to optimizing the bonding pressure and duration.

Author Contributions: H.M. and L.L. conceived and designed the experiments; H.M. performed the experiments; H.M. and X.L. analyzed the data; H.M. wrote the paper; X.Y. and H.A.M. contributed to the revision of the paper. All authors have read and agreed to the published version of the manuscript.

Funding: This research received no external funding.

Conflicts of Interest: The authors declare no conflict of interest.

\section{References}

1. Guoge, Z.; Chandel, R.S.; Pheow, S.H.; Hoon, H.H. Effect of Bonding Temperature on the Precipitation of $\delta$ Phase in Diffusion Bonded Inconel 718 Joints. Mater. Manuf. Process. 2006, 21, 453-457. [CrossRef]

2. Pouranvari, M.; Ekrami, A.; Kokabi, A.H. Transient liquid phase bonding of wrought Inconel 718 nickel based superalloy using standard heat treatment cycles: Microstructure and mechanical properties. Mater. Des. 2013, 50, 694-701. [CrossRef]

3. Han, W.B.; Zhang, K.F.; Wang, B.; Wu, D.Z. Superplasticity and diffusion bonding of Inconel 718 superalloy. Acta Metall. Sin. Engl. Lett. 2007, 20, 307-312. [CrossRef]

4. Pouranvari, M.; Ekrami, A.; Kokabi, A.H. Solidification and solid state phenomena during TLP bonding of Inconel 718 superalloy using Ni-Si-B ternary filler alloy. J. Alloys Compd. 2013, 563, 143-149. [CrossRef]

5. Yeh, M.S.; Chuang, T.H. Low-pressure diffusion bonding of SAE 316 stainless steel by inserting a superplastic interlayer. Scr. Mater. 1995, 33, 1277-1281. [CrossRef]

6. Guoge, Z.; Chandel, R.S.; Pheow, S.H. Solid state diffusion bonding of Inconel 718. Sci. Technol. Weld. Join. 2001, 6, 235-239.

7. Li, Z.R.; Liu, B.; Zhang, X.L.; Feng, J.C. Microstructure and Mechanical Property of GH4169 Joints by Vacuum Diffusion Bonding. International Conference on Advanced Design and Manufacturing Engineering, Guangzhou, China. Adv. Mater. Res. 2011, 1379, 1180-1183.

8. Pouranvari, M.; Ekrami, A.; Kokabi, A.H. Aging response of transient liquid phase bonded wrought Inconel 718 superalloy: Influence of post-bond heat treatment. Sci. Technol. Weld. Join. 2014, 19, 105-110. [CrossRef]

9. Pouranvari, M.; Ekrami, A.; Kokabi, A.H. TLP bonding of cast Inconel 718 nickel based superalloy: Process-microstructure-strength characteristics. Mater. Sci. Eng. A Struct. 2013, 568, 76-82. [CrossRef]

10. Zhang, B.; Chen, X.; Pan, K.X.; Wang, J.N. Multi-Objective Optimization of Friction Stir Spot-Welded Parameters on Aluminum Alloy Sheets Based on Automotive Joint Loads. Metals 2019, 9, 520. [CrossRef]

11. Costa, P.; Altamirano, G.; Salinas, A.; Gonzalez-Gonzalez, D.S.; Goodwin, F. Optimization of the Continuous Galvanizing Heat Treatment Process in Ultra-High Strength Dual Phase Steels Using a Multivariate Model. Metals 2019, 9, 703. [CrossRef]

12. Su, Y.; Zhao, G.Y.; Zhao, Y.G.; Meng, J.B.; Li, C.X. Multi-Objective Optimization of Cutting Parameters in Turning AISI 304 Austenitic Stainless Steel. Metals 2020, 10, 217. [CrossRef]

13. Kim, I.S.; Jeong, Y.J.; Lee, C.W.; Yarlagadda, P.K.D.V. Prediction of Welding Parameters for Pipeline Welding Using an Intelligent System. Int. J. Adv. Manuf. Technol. 2002, 2, 32-35. [CrossRef]

14. Su, C.T.; Chiang, T.L. Optimizing the IC wire bonding process using a neural networks/genetic algorithms approach. J. Intell. Manuf. 2003, 14, 229-238. [CrossRef]

15. Okuyucu, H.; Kurt, A.; Arcaklioglu, E. Artificial neural network application to the friction stir welding of aluminum plates. Mater. Des. 2005, 28, 78-84. [CrossRef]

16. Pal, S.; Pal, S.K.; Samantaray, A.K. Artificial neural network modeling of weld joint strength prediction of a pulsed metal inert gas welding process using arc signals. J. Mater. Process. Technol. 2007, 202, 464-474. [CrossRef] 
17. Srinivas, K.; Vundavilli, P.R.; Hussain, M.M.; Saiteja, M. Prediction of Welded Joint Strength in Plasma Arc Welding: A Comparative Study Using Back-Propagation and Radial Basis Neural Networks. In IOP Conference Series: Materials Science and Engineering, Proceedings of the International Conference on Advances in Materials and Manufacturing Applications, Bangalore, India, 14-16 July 2016; IOP: Bristol, UK, 2016; Volume 149, p. 012033.

18. Britto, A.S.F.; Raj, R.E.; Mabel, M.C. Prediction of shear and tensile strength of the diffusion bonded AA5083 and AA7075 aluminium alloy using ANN. Mater. Sci. Eng. A Struct. 2017, 692, 1-8. [CrossRef]

19. Lin, H.L. Optimization of Inconel 718 alloy welds in an activated GTA welding via Taguchi method, gray relational analysis, and a neural network. Int. J. Adv. Manuf. Technol. 2013, 67, 939-950. [CrossRef]

20. Zhang, L.L. Formation mechanisms of high quality diffusion bonded martensitic stainless steel joints. Sci. Technol. Weld. Join. 2015, 20, 115-122. [CrossRef]

(C) 2020 by the authors. Licensee MDPI, Basel, Switzerland. This article is an open access article distributed under the terms and conditions of the Creative Commons Attribution (CC BY) license (http://creativecommons.org/licenses/by/4.0/). 